\title{
Zfat Is Indispensable for the Development of Erythroid Cells in the Fetal Liver
}

\author{
KEIKO DOI ${ }^{1,2}$, TOSHIYUKI TSUNODA ${ }^{1,2}$, MIDORI KOYANAGI $^{1,2}$, YOKO TANAKA $^{1,2}$, SHIORI YAMANO $^{1}$, \\ AYA FUJIKANE ${ }^{1}$, KENSUKE NISHI $^{1}$, SHUHEI ISHIKURA $^{1,2}$ and SENJI SHIRASAWA ${ }^{1,2}$ \\ ${ }^{1}$ Department of Cell Biology, Faculty of Medicine, and \\ ${ }^{2}$ Central Research Institute for Advanced Molecular Medicine, Fukuoka University, Fukuoka, Japan
}

\begin{abstract}
Background/Aim: In mice, fetal liver is the first tissue of definitive erythropoiesis for definitive erythroid expansion and maturation. ZFAT, originally identified as a candidate susceptibility gene for autoimmune thyroid disease, has been reported to be involved in primitive hematopoiesis and $T$ cell development. The aim of this study was to examine whether or not Zfat is involved in definitive erythropoiesis in the fetal liver during mammalian development. Materials and Methods: The role of $Z$ fat during mouse fetal erythropoiesis in the fetal liver was examined using tamoxifen-inducible CreERT2 Zfat-deficient mice. Results: Zfat-deficient mice exhibit moderate anemia with small and pale fetal liver through a decreased number of erythroblasts by E12.5. Apoptosis sensitivity in fetal liver erythroid progenitors was enhanced by Zfat-deficiency ex vivo. Moreover, Zfat knockdown partially inhibited $C D 71^{-/ l o w}$ Ter $119^{-}$to $C D 71^{\text {high }}$ Ter $119^{-}$ transition of fetal liver erythroid progenitors with impairment in the elevation of CD71 expression. Conclusion: Zfat plays a critical role for erythropoiesis in the fetal liver.
\end{abstract}

We previously identified ZFAT (zinc-finger gene with AThook/zinc-finger gene in autoimmune thyroid disease susceptibility region) as a susceptibility gene for autoimmune thyroid disease (1). ZFAT encodes a highly conserved protein containing both AT-hook domain and zinc-finger motifs (2). Zfat protein is expressed at high levels in lymphoid tissues (thymus, spleen, lymph node tissues) (2). We have reported that Zfat knock-out $\left(\mathrm{Zfat}^{--}\right)$mouse is embryonic lethal by embryonic day (E) 8.5 and that Zfat is essential for early embryonic development as a transcriptional regulator of primitive

Correspondence to: Keiko Doi, Ph.D., Department of Cell Biology, Faculty of Medicine, Fukuoka University, 7-45-1 Nanakuma, Jonanku, Fukuoka 814-0180, Japan. Tel: +81 928011011, e-mail: kdoi@fukuoka-u.ac.jp

Key Words: Zfat, transcription factor, definitive erythropoiesis, fetal liver. hematopoiesis $(3,4)$. We also found that ZFAT is implicated in apoptotic modulation in human leukemia MOLT-4 cells (5) and murine embryonic fibroblasts (6), and in the development of human umbilical vein endothelial cells (7). Additionally, several genetic variants of ZFAT have been reported to be associated with the severity of Hashimoto's disease (HD) (8), with height in adult Japanese and Korean populations $(9,10)$ and with several diseases including cancer and hypertension $(11,12)$. Recent studies demonstrated that $Z F A T$ is a novel imprinted gene expressed in the human placenta (13), and that ZFAT gene is over-expressed in unruptured aneurysms, suggesting that ZFAT could potentially be used as a predictive molecular marker of high risk of aneurysm rupture in peripheral blood (14). Following the identification and cloning of ZFAT, the major physiological and disease-associated roles of ZFAT were revealed. In our recent studies, we have reported that Zfat is critical for both T-cell development in the thymus and peripheral T-cell homeostasis, and transcriptional profiling revealed a novel molecular mechanism in T-cell homeostasis (15-18).

Our previous work suggested that Zfat is also involved in definitive erythropoiesis. In a study using a reporter mouse system, Zfat was shown to be highly expressed at erythroid progenitor cells in the fetal liver at E12.5 (19). Conventional Zfat-knockout mice are lethal by E8.5 before fetal erythropoiesis is established (3), which prevents a determination of the role of Zfat in definitive erythropoiesis. In this article, we used a conditional Zfat-knockout mouse model to determine how the loss of Zfat affects definitive erythropoiesis. We analyzed the phenotype of embryos in which Zfat was conditionally deleted from E6.5 onward. Our results showed that loss of Zfat disrupts definitive erythropoiesis in the fetal liver, causing anemia due to defects in the differentiation and survival of erythroid progenitor cells.

\section{Materials and Methods}

Mice. The mouse lines $Z$ fat $t^{\text {flox/flox }}\left(\mathrm{Zfat}^{\mathrm{f} / \mathrm{f}}\right)(15)$, CreERT2-Zfat $t^{\text {flox/flox }}$ $\left(\right.$ CreERT2-Zfat $\left.{ }^{\mathrm{f} / \mathrm{f}}\right)(20)$ and $Z f a t^{\mathrm{ZsGreen} /+}(\mathrm{Zfat} \mathrm{ZsG/+})(19)$ have been described previously. CreERT2-Zfat $\mathrm{f}^{\mathrm{f} / \mathrm{f}}$ and $Z f a t^{\mathrm{flox} / \mathrm{w}}$ mice were established from mice with a C57BL/6J genetic background. 
CreERT2-Zfat $\mathrm{t}^{\mathrm{f} / \mathrm{f}}$ males were crossed with $Z \mathrm{fat}^{\mathrm{f} / \mathrm{w}}$ females. In staging the embryos, E0.5 was defined as noon of the day on which a copulatory plug was found after overnight mating. For induction of Cre-mediated recombination in embryos, tamoxifen (Sigma-Aldrich, St. Louis, MO, USA) in sunflower oil (Sigma-Aldrich) was injected intraperitoneally into pregnant $Z \mathrm{fat}^{\mathrm{f} / \mathrm{w}}$ mice ( 8 to $14 \mathrm{wk}$ ) at a dosage of $2 \mathrm{mg}$ (with $0.94 \mathrm{mg}$ progesterone) $/ 25 \mathrm{~g}$ of body weight at E6.5. All the experiments on mice were carried out under the guidelines of the Institutional Animal Care and Use Committee of Fukuoka University.

Flow cytometry. Fetal livers dissected from E12.5 embryos were dispersed into a single-cell suspension by gentle pipetting. Isolated fetal liver cells were immunostained at $4^{\circ} \mathrm{C}$ in $\mathrm{PBS} / 3 \% \mathrm{FBS}$ in the presence of anti-mouse CD16/CD32 Abs (BD Pharmingen, Oxford, UK) to block Fc receptors. The antibodies used were anti-CD71 (C2) from BD Bioscience, anti-DLK1 from R\&D Systems (Minneapolis, MN, USA), anti-cKit (2B8) from eBioscience (San Diego, CA, USA) and antiTER119 (TER-119) from BioLegend (San Diego, CA, USA)). Apoptotic cells were analyzed using an FITC Annexin V Apoptosis Detection Kit I (BD Biosciences, San Jose, CA, USA), 7-AAD (BD Bioscience) and APC-conjugated anti-Annexin V antibody (BioLegend) according to the manufacturers' protocols. Flow cytometry analysis was performed on a Becton Dickinson FACSAria II with FACS Diva software. Analyses of all flow cytometry data were done using FlowJo version 10 software (Tomy Digital Biology, Tokyo, Japan).

Ex vivo erythroid differentiation and apoptosis sensitivity assay. Sorted c-Kit ${ }^{+}-\mathrm{P} 1$ (c-Kit $^{+} \mathrm{CD} 71^{-/ \text {low }}$ TER119-) cells were seeded onto fibronectin-coated plates (CORNING, NY, USA) in IMDM (Thermo Fisher Scientific, Waltham, MA, USA)/20\% FBS, $100 \mu \mathrm{M} 2$ mercaptoethanol (Sigma-Aldrich), $50 \mathrm{ng} / \mathrm{ml} \mathrm{SCF}$ (R\&D Systems) and $10 \mathrm{ng} / \mathrm{ml} \mathrm{IL-3} \mathrm{(R \& D} \mathrm{Systems).} \mathrm{After} 24 \mathrm{~h}$, the cells were infected with retroviruses against $Z$ fat (18) and the culture medium was exchanged with a medium containing $2 \mathrm{U} / \mathrm{ml}$ EPO (MYBioSource, San Diego, CA, USA), $5.5 \mu \mathrm{g} / \mathrm{ml}$ transferrin (Thermo Fisher Scientific) and 10 $\mu \mathrm{g} / \mathrm{ml}$ insulin (Thermo Fisher Scientific) to induce terminal erythroid differentiation. After $48 \mathrm{~h}$ induction, cells were stained with the antibodies described above and analyzed by flow cytometry.

In the apoptosis sensitivity assay, sorted $\mathrm{c}-\mathrm{Kit}^{+}-\mathrm{R} 1$ (c-Kit $^{+}$ CD71-/low TER119-) cells were seeded onto fibronectin-coated plates (CORNING) in IMDM (Thermo Fisher Scientific)/20\% FBS, $100 \mu \mathrm{M}$ 2-mercaptoethanol (Sigma-Aldrich), $50 \mathrm{ng} / \mathrm{ml} \mathrm{SCF}$ (R\&D Systems) and $10 \mathrm{ng} / \mathrm{ml} \mathrm{IL-3} \mathrm{(R \& D} \mathrm{Systems)} \mathrm{and} \mathrm{were} \mathrm{treated} \mathrm{with}$ 4-hydroxytamoxifen (4OHT; Sigma-Aldrich) for $72 \mathrm{~h}$ at concentrations ranging from 0 to $0.6 \mu \mathrm{M}$.

Immunoblotting. Immunoblotting was performed as described previously (2).

Statistical analysis. The data are presented as mean \pm standard deviation. Statistical analyses were performed using an unpaired two-tailed Student's $t$-test. Differences at $p<0.05$ were considered to be statistically significant.

\section{Results}

Zfat deletion by the injection of tamoxifen leads to a decrease in fetal liver size and anemia. To clarify the physiologic function of Zfat in definitive erythropoiesis in the fetal liver, we performed an analysis using tamoxifen-inducible
CreERT2 Zfat-deficient mice (20), in which exon 8 of Zfat gene was deleted. Tamoxifen was injected intraperitoneally into pregnant $Z f a t^{\mathrm{f} / \mathrm{w}}$ mice at E6.5 (Figure 1A). We confirmed that a single injection of tamoxifen into pregnant mice caused a deficiency of Zfat within the fetal liver of the tamoxifeninducible CreERT2-Zfat ${ }^{\mathrm{f} / \mathrm{f}}$ embryos by E12.5 (Figure 1B). CreERT2-Zfat ${ }^{\mathrm{f} / \mathrm{f}}$ embryos at E12.5 were slightly pale, and their fetal livers, the main site of fetal erythropoiesis, were significantly smaller than those of the littermate controls (Figure 1C). The cell numbers in CreERT2-Zfat $\mathrm{f}^{\mathrm{f} / \mathrm{f}}$ fetal livers were significantly reduced compared with those in CreERT2$Z f a t^{\mathrm{f} / \mathrm{w}}$ fetal livers $\left(0.75 \pm 0.11 \times 10^{6}\right.$ vs. $3.2 \pm 0.24 \times 10^{6}$, $p<0.0001$ ) (Figure 1D, top).

To explain the decreased number of fetal liver cells at the cellular level, we investigated the hematopoietic (early definitive erythroblastic) (21), erythropoietic and hepatic compartments in fetal liver by flow cytometry using c-Kit, Ter119 and Dlk1 (22) as surface markers. Flow cytometric analysis of fetal livers at E12.5 revealed a 6.3-fold reduction in the Ter $119^{+}$erythroid cell fraction and a 4.0 -fold reduction in the $\mathrm{c}-\mathrm{Kit}^{+}$hematopoietic progenitor fraction (Figure 1D). Because the total number of CreERT2-Z $\mathrm{fat}^{\mathrm{f} / \mathrm{f}}$ fetal liver cells was decreased to $23 \%$ of the control, the absolute number of Ter $119^{+}$erythroid cells was decreased by $85 \%$ in CreERT2$\mathrm{Zfat}^{\mathrm{f} / \mathrm{f}}$ fetal livers compared with control fetal livers. The absolute number of Dlk $1^{+}$hepatoblasts was reduced to $29 \%$ of the control. Because our previous analyses of the reporter mouse system revealed that Zfat was expressed in Dlk1 ${ }^{+}$ hepatoblasts cells (Figure 1E) and $\mathrm{c}-\mathrm{Kit}^{+}$hematopoietic progenitor cells (19) of the fetal liver at E12.5, we considered that the $Z$ fat-deficiency affected the numbers of these cells in CreERT2-Zfat ${ }^{\mathrm{f} / \mathrm{f}}$ fetal livers. In contrast to the absolute numbers of Ter $119^{+}, \mathrm{Dlk}^{+}$and $\mathrm{c}-\mathrm{Kit}^{+}$cells, the relative numbers of $\mathrm{Dlk} 1^{+}$and $\mathrm{c}-\mathrm{Kit}^{+}$cells were not disturbed except for an approximate 1.48-fold decrease in Ter119+ erythroid cells (Figure1D, bottom). These results indicated that growth retardation of the fetal liver in CreERT2-Zfat ${ }^{\mathrm{f} / \mathrm{f}}$ embryos was mainly attributable to a reduction in the number of erythroid lineage cells.

Zfat-deficiency impairs erythroid differentiation in the fetal liver at E12.5. To further examine the causes of blocking of erythroid differentiation, we analyzed each stage of erythroid cell maturation in the developing fetal liver. A flow cytometric system has been used to identify consecutive developmental stages of erythroid maturation in the fetal liver based on the expression of Ter119 and CD71 (23). In another study, combinatorial staining with the cell surface markers CD71, Ter119 and c-Kit was used to stage erythroid maturation in vivo (24). We divided fetal liver cells into four CD71/Ter119 regions that represented the different stages of erythroid development; we termed these stages R1 to R4 (Figure 2A). A density plot of Ter119 and CD71 staining of cells dispersed from a fetal 
liver (E12.5, CreERT2-Zfat ${ }^{\mathrm{f} / \mathrm{w}}$ and CreERT2-Zfat ${ }^{\mathrm{f} / \mathrm{f}}$ ) is shown in Figure 2A. The maturation state of erythroid cells revealed reduced frequencies of chromatophilic erythroblasts, orthochromatophilic erythroblasts and reticulocytes at the R4 stage in CreERT2-Zfat f// fetal livers, with R3 cells (basophilic erythroblasts) constituting the point at which the erythrocyte maturation process was blocked (Figure 2A). The absolute number of chromatophilic erythroblasts, orthochromatophilic erythroblasts and reticulocytes at the $\mathrm{R} 4$ stage was reduced to $7 \%$ of the control. The reductions in R1, R2 and R3 cells were moderate but significant in CreERT2-Zfat ${ }^{\mathrm{f} / \mathrm{f}}$ mice $(29.4 \%$ (R1), $32.8 \%(\mathrm{R} 2)$ and $41.9 \%(\mathrm{R} 3)$ of the corresponding numbers in the control) (Figure 2B). The expression of CD71 and Ter119 was lower on fetal liver cells in CreERT2-Zfat ${ }^{\mathrm{f} / \mathrm{f}}$ mice (thick black line) than on fetal liver cells in CreERT2-Zfat ${ }^{\mathrm{f} / \mathrm{w}}$ mice (dark gray area) (Figure 2C). These findings revealed that a defect in definitive erythropoiesis in CreERT2-Zfat ${ }^{\mathrm{f} / \mathrm{f}}$ fetal liver was the cause of anemia.

Zfat-deficiency affected erythroid differentiation and apoptosis sensitivity in c-Kit ${ }^{+}-R 1$ progenitor cells ex vivo. Fetal liver cells negative for Ter119 (a mature erythroid cell marker) are primarily erythroid progenitor cells and proerythroblasts with the potential for proliferation and differentiation by ex vivo culture (24). We investigated the intrinsic role of Zfat in erythroid differentiation by this ex vivo culture system. Zfat is expressed at high levels in c-Kit ${ }^{+}-\mathrm{R} 1\left(\mathrm{CD} 71^{-/ \mathrm{low}^{-}} \mathrm{Ter} 119^{-}\right)$cells and c-Kit ${ }^{+}-\mathrm{R} 2\left(\mathrm{CD} 71^{\text {high }}\right.$ Ter119-) cells (19). We therefore examined whether, in the context of $\mathrm{R} 2$ cells, Zfat might be required for the R1 to R2 transition. For this purpose, we prevented Zfat expression in $\mathrm{c}-\mathrm{Kit}^{+}-\mathrm{R} 1$ cells mediated by the $\mathrm{Cre} /$ loxP system during their incubation in stem-cell factor (SCF) medium (Figure 3A, top). The c-Kit ${ }^{+}-\mathrm{R} 1$ cells sorted from $\mathrm{Zfat}^{\mathrm{f} / \mathrm{f}}$ fetal liver at E12.5 were infected with retroviral vectors expressing Cre recombinase-IRES-ZsGreen (CreZsGreen) or ZsGreen (control) (18). To allow expression of the transduced Cre-ZsGreen or ZsGreen, infected cells were cultured for $48 \mathrm{~h}$ in SCF and interleukin 3 (IL-3), which are known to sustain the viability of progenitors. Infected c-Kit ${ }^{+}-$ $\mathrm{R} 1$ cells were then transferred to medium containing erythropoietin (EPO) for $48 \mathrm{~h}$ (Figure $3 \mathrm{~A}$, bottom). The analysis of the R1 to R2 transition showed that the frequency of R2 cells transduced by Cre-ZsGreen was moderately reduced by $24.0 \%$ compared with the control (from $40.5 \pm 5.4 \%$ for the control to $30.7 \pm 1.7$ following Cre-ZsGreen transduction; $p=0.133$ ) and lower CD71 levels were expressed within the R2 subset (Figure 3B). These results indicated that Zfat knockdown partially inhibited R1 to R2 transition of fetal liver erythroid progenitors with impairment in elevation of CD71 expression during R1 to R2 transition.

We also examined the effect of Zfat-deficiency on apoptosis during the proliferation of $\mathrm{c}-\mathrm{Kit}^{+}-\mathrm{R} 1$ cells sorted from the CreERT2-Zfat ${ }^{\mathrm{f} / \mathrm{f}}$ fetal liver and CreERT2-Zfat ${ }^{\mathrm{f} / \mathrm{w}}$ fetal liver (control) at E12.5 (Figure 3C, left). We incubated sorted c-Kit ${ }^{+}-\mathrm{R} 1$ cells with a concentration gradient 4hydroxytamoxifen (4OHT) in consideration of the cytotoxic effect of 4OHT. We observed that c-Kit ${ }^{+}-\mathrm{R} 1$ cells from CreERT2-Z fat $^{\mathrm{f} / \mathrm{f}}$ fetal liver had a dose-dependent elevation of Annexin V-positive $\left(7 \mathrm{AAD}^{-}\right)$cells in response to $4 \mathrm{OHT}$ treatment in a range from 0 to $0.6 \mu \mathrm{M}$. Flow cytometric assay of c-Kit ${ }^{+}-\mathrm{R} 1$ cells from CreERT2-Zfat ${ }^{\mathrm{f} / \mathrm{f}}$ fetal liver showed an enhancement of apoptosis sensitivity to $4 \mathrm{OHT}$ treatment at concentrations greater than $0.1 \mu \mathrm{M}(15.6 \pm 1.2 \%$ vs. $11.9 \pm 0.6 \%$ (control) at $0.1 \mu \mathrm{M}, p<0.07$; and $19.0 \pm 1.9 \%$ vs. $14.1 \pm 0.7 \%$ (control) at $0.2 \mu \mathrm{M}, p<0.09$ ) (Figure $3 \mathrm{C}$, right). These results suggested that the elevation of apoptosis sensitivity by Zfatdeficiency in c-Kit ${ }^{+}-\mathrm{R} 1$ cells may reflect enhancement of apoptosis sensitivity prior to R1 to R2 transition in fetal liver.

\section{Discussion}

Zfat has been previously shown to be an essential factor in early mouse development (3). It is well known that the fetal liver plays a critical role as a major tissue for rapid amplification of definitive erythrocytes during mouse development, but whether Zfat is involved in definitive erythropoiesis in the fetal liver remains unknown. In this study, we found that Zfat is required for the development of definitive erythrocytes in the developing fetal mouse liver. Three major waves of erythropoietic potential emerge consecutively during mouse embryogenesis. The first wave arises in the yolk sac in mice and humans and generates initially primitive erythroid cells $(21,25,26)$. The second wave also occurs in the yolk sac, but it generates definitive erythroid lineages that are distinguishable from primitive erythroid cells (27). The primitive erythroid cells are outnumbered by the drastically expanding number of definitive erythroid cells generated from the developing fetal liver $(23,28)$. The third wave emerges from hematopoietic stem cells, which expand in the fetal liver and ultimately seed the bone marrow $(29,30)$. Our data indicate that fetal livers from CreERT2-Zfat ${ }^{\mathrm{f} / \mathrm{f}}$ embryos injected with tamoxifen at E6.5 are smaller and paler than those of their control littermates at E12.5. Zfat is involved in the rapid expansion of definitive erythroid progenitor numbers in the early fetal liver around E12.5, suggesting that Zfat is an integral component for initiation of the second wave of erythropoiesis. In addition, to define the embryonic period when Zfat regulates development of definitive erythrocytes in the developing fetal mouse liver, we treated pregnant mice by an injection at E7.5. Intriguingly, Zfat-deficiency by the injection at E7.5 slightly compromised liver development at E12.5, and flow cytometric analysis showed modest changes in erythropoiesis (data not shown). These results may indicate that Zfat is required within a specific developmental time window. Additional studies are needed to elucidate the 
A

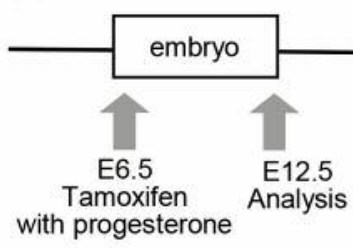

C $\quad$ E12.5

CreERT2 CrEERT2 -Zfat th ${ }^{\text {f }}$-Zfat fif

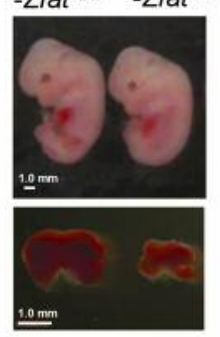

D
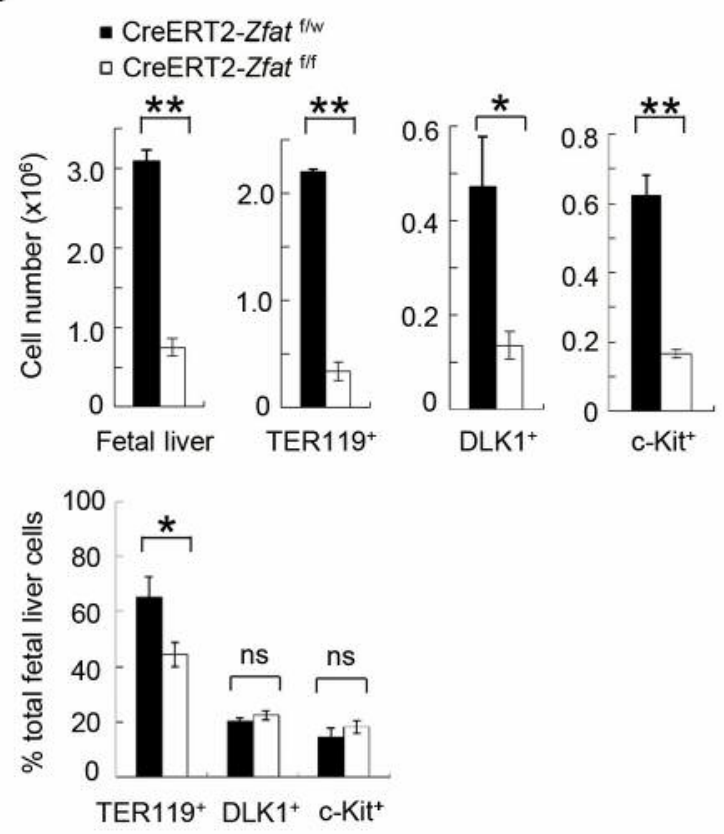

Figure 1. Zfat deletion by the injection of tamoxifen at E6.5 leads to a decrease in fetal liver size and anemia. (A) Schematic illustrating the time of Zfat deletion from mice via tamoxifen injection and the times at which necropsy was performed. (B) Lysates were prepared from E12.5 liver of CreERT2-Zfatf/f or CreERT2-Zfatf/w (control) embryos and analyzed by western blotting using anti-Zfat (top) or anti- $\beta$-Actin (bottom) antibodies. (C) Phenotypic appearance of CreERT2-Zfat flf and CreERT2-Zfat f/w (control) embryos at E12.5. Tamoxifen was injected intraperitoneally using a dosage of $2 \mathrm{mg} / 25 \mathrm{~g}$ of body weight at E6.5. Fetal livers of CreERT2-Zfatif and control embryos at E12.5 are shown. The bar represents $1.0 \mathrm{~mm}$. (D) Absolute numbers (top) and frequency (bottom) of total fetal liver, TER $119^{+}, \mathrm{DLK1}^{+}$and c-Kit ${ }^{+}$cells in fetal liver from CreERT2-Zfat flf and CreERT2-Zfat f/w (control) embryos at E12.5. Data are expressed as mean $\pm S D ; n \geq 3$ mice per group. ${ }^{*} p<0.01$, $* * p<0.001, n s$ : Not significant. (E) ZsGreen signals in DLK1+ cells from

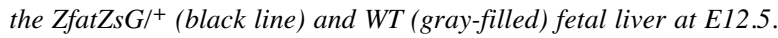

A

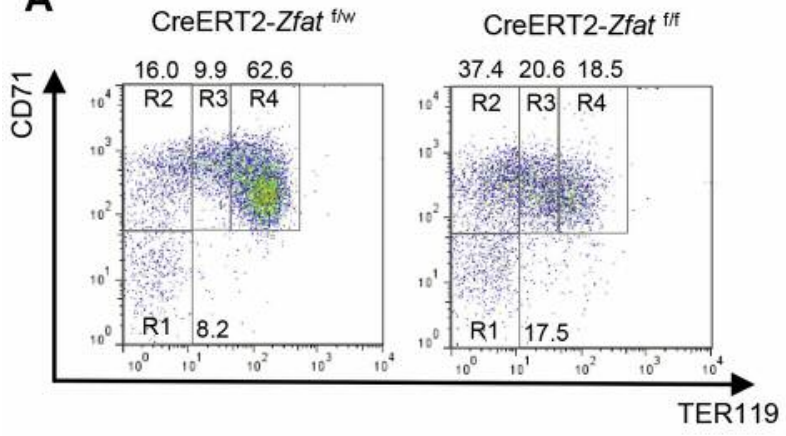

B

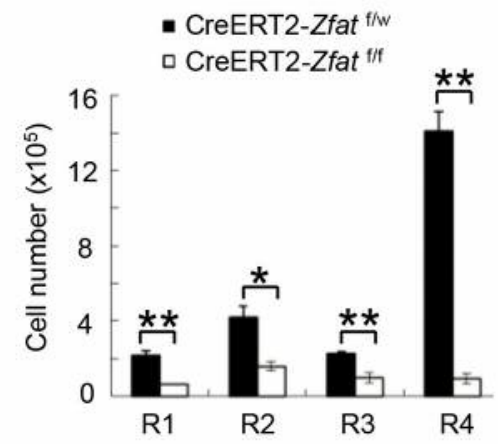

C Gray-filled: CreERT2-Zfat five Line: CreERT2-Zfat ${ }^{\text {fff }}$
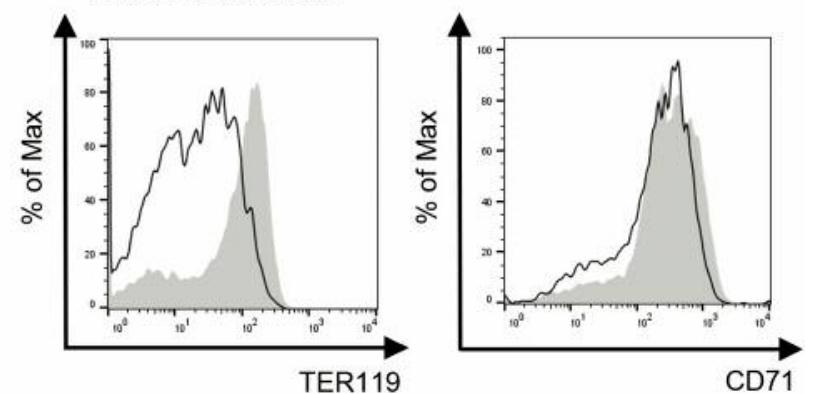

Figure 2. Zfat-deficiency results in a defect in definitive erythropoiesis of the fetal liver at E12.5. (A) Flow cytometric analysis of Ter119 and CD71 expression in E12.5 fetal livers. Flow cytometric profiles of erythroid differentiation defined by CD71 and Ter119 expression in representative fetal livers from CreERT2-Zfat f/f and CreERT2-Zfat f/w (control) embryos at E12.5. Regions R1 to R4 are characterized by the $C D 71$ and Ter119 expression profile. The cells in each region can be classified morphologically into erythroid progenitor cells and proerythroblasts (R1), proerythroblasts (R2), basophilic erythroblasts (R3), chromatophilic erythroblasts, orthochromatophilic erythroblasts and reticulocytes $(R 4)(24,37,38)$. The percentage of each fraction is indicated. (B) Absolute cell numbers in fetal livers from CreERT2-Zfat fif and CreERT2-Zfat f/w (control) embryos at E12.5. Quantification and statistical analysis of $C D 71$ and Ter119 by flowcytometry analysis. Data are expressed as mean $\pm S D ; n \geq 3$ embryos per group. ${ }^{*} p<0.005$, $* * p<0.001$. (C) Flow cytometric analysis of fetal livers from CreERT2Zfat flf and CreERT2-Zfat f/w (control) embryos at E12.5. Representative histograms showing the expression of Ter119 (left) and CD71 (right) in fetal livers from CreERT2-Zfatflf (thick black line) and CreERT2-Zfat f/w (dark gray area) embryos at E12.5. 
A Zfat ${ }^{f / w}$ embryos

Fetal liver (E12.5
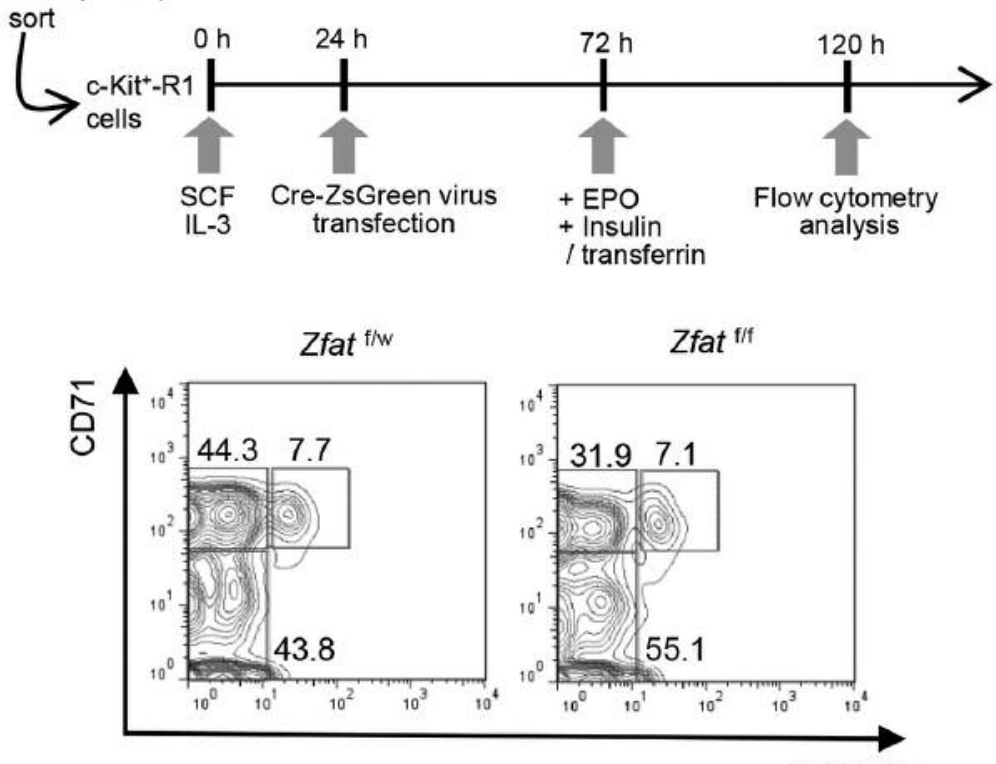

B

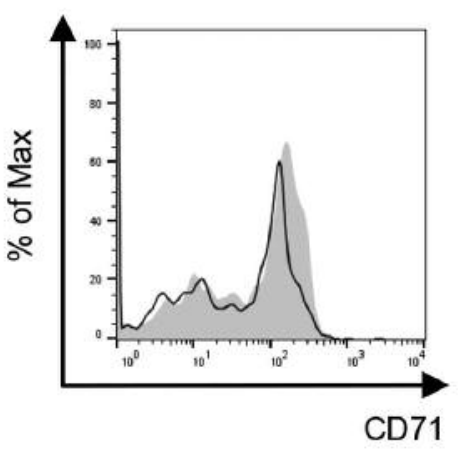

TER119

C
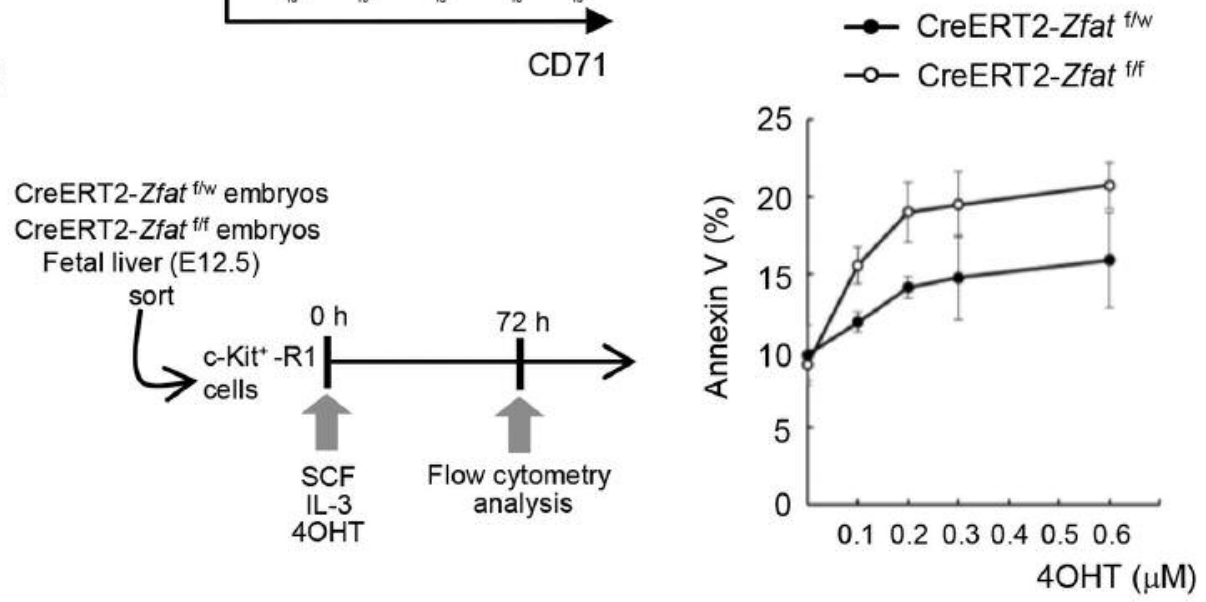

Figure 3. The intrinsic effect of Zfat-deficiency on erythroid differentiation and apoptosis sensitivity in c-Kit ${ }^{+}$-R1 cells. (A) Zfat knockdown in progenitor cells within fetal liver. $c-$ Kit $^{+}-R 1$ (c-Kit ${ }^{+}$CD $71^{- \text {llow }}$ TER119-) cells were sorted from fetal livers at E12.5 and cultured in the presence of $I L-3$ and SCF. After $24 \mathrm{~h}$, cells were infected with retroviruses for Zfat-deficiency and the medium was exchanged with medium containing EPO to induce erythroid differentiation. After $48 \mathrm{~h}$ induction culture, cells were stained with antibodies against CD71 and Ter119 and analyzed by flow cytometry (top). The Zfat-deficient cells were examined for the expression of ZsGreen as a marker antigen for infection. The flow cytometric profiles of ZsGreen ${ }^{+}$ cells by the expression of $C D 71$ and Ter119 are indicated (bottom). The percentage of each fraction is indicated. (B) Flow cytometric analysis for CD71 in c-Kit ${ }^{+}-R 1$ incubated with EPO for $48 \mathrm{~h}$. (C) Annexin $V$-positive $\left(7 A A D^{-}\right)$cells measured by flow cytometric analysis (right). $c$-Kit ${ }^{+}-R 1$ cells in fetal livers from CreERT2-Zfat flf and CreERT2-Zfat f/w embryos were treated with a range of concentrations of $4 O H T$ up to $0.6 \mu M$ for $72 \mathrm{~h}$ (left). 
developmental process of definitive erythropoiesis during mouse embryogenesis according to the functions of Zfat.

Our data showed that Zfat-knockdown partially inhibited

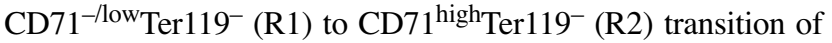
fetal liver erythroid progenitors with an impairment in elevation of CD71 expression during R1 to R2 transition. Previous studies have indicated that Zfat expression during $\mathrm{CD}^{+} \mathrm{T}$ cell proliferation is elevated according to synchronization in the Sphase (5) and that Zfat is highly expressed in c-Kit ${ }^{+}-\mathrm{R} 1$

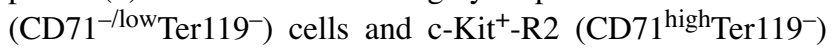
cells (19). In mouse fetal erythropoiesis, the initial upregulation of cell surface CD71 identifies developing erythroblasts that are tightly synchronized in S-phase (31). The transition from R1 (CD71 ${ }^{-/ \text {low }}$ Ter119 $)$ to $\mathrm{R} 2\left(\mathrm{CD}^{-} 1^{+}\right.$Ter119-) occurred during the $\mathrm{S}$-phase and required both EPO and S-phase progression (31). The function and mechanism of Zfat may partly underlie the transcription network in erythroid differentiation, which could be related to the drastic change of expression of transcription factors in erythroblasts that are closely synchronized in S-phase. Moreover, c-Kit is a proto-oncogene that is upregulated in cancer cells, leading to its kinase activation and eventually to a disruption of regulated proliferation (32). The major triggering events for erythroleukemia are the disruption of epigenetic and microRNA regulation, and transcript regulation leading to dysregulation of differentiation and interruption of apoptosis for pro-erythroblasts (33). The critical effects of the interactions with transcription factors are revealed during initial differentiation, and disorganized differentiation may underlie the leukemogenic mechanisms of maturation arrest through dysregulated expression of these transcription factors (34). Collectively, the above facts and conjectures suggest that Zfat may also play a role in regulating the proliferation of erythroid progenitors and erythropoietic homeostasis through transcript regulation, the dysfunction of which could lead to the occurrence of leukemia.

In our recent study, to define the cell-intrinsic mechanisms of $\mathrm{T}$ cell homeostasis, we investigated which molecules are regulated by expression of the Zfat gene. Using ChIP-seq analysis and gene expression data during $\mathrm{CD}^{+} \mathrm{T}$ cell proliferation, several genes, including Brpf1, were identified as Zfat-regulated genes (18). The development of erythroid cells is determined by a network including transcription factors $(35,36)$. However, the mechanisms responsible for the complicated regulation of Zfat in erythroid progenitors of fetal liver according to the stages of erythroid differentiation have not been investigated. Further studies are needed to identify and characterize the intrinsic pathways leading to Zfat-deficiency and its regulating genes, and to define the molecular mechanism of Zfat-mediated regulation of erythroid differentiation in fetal liver. In addition, further studies would be expected to elucidate the important role of $\mathrm{Zfat}$ in the development of erythroid lineages in bone marrow.

\section{Conflicts of Interest}

The Authors have no conflict of interest in regard to this study.

\section{Authors' Contributions}

KD designed and carried out the experiment with help of SY and $\mathrm{AF}$ and wrote the article. MK, YT, SY, AF, KN and SI contributed to sample preparation and the interpretation of results. SS and TT supervised the study. All Authors reviewed the manuscript.

\section{Acknowledgements}

The Authors thank Yumiko Hirose and Takami Danno for technical assistance. This work was supported in part by a Scientific Research (C) from the Japan Society for the Promotion of the Science and a Grant-in-Aid for the FCAM from the Ministry of Education, Culture, Sports, Science and Technology (MEXT)-Supported Program for the Strategic Research Foundation at Private Universities.

\section{References}

1 Shirasawa S, Harada H, Furugaki K, Akamizu T, Ishikawa N, Ito K, Ito K, Tamai H, Kuma K, Kubota S, Hiratani H, Tsuchiya T, Baba I, Ishikawa M, Tanaka M, Sakai K, Aoki M, Yamamoto K and Sasazuki T: SNPs in the promoter of a B cell-specific antisense transcript, SAS-ZFAT, determine susceptibility to autoimmune thyroid disease. Hum Mol Genet 13(19): 22212231, 2004. PMID: 15294872. DOI: 10.1093/hmg/ddh245

2 Koyanagi M, Nakabayashi K, Fujimoto T, Gu N, Baba I, Takashima Y, Doi K, Harada H, Kato N, Sasazuki T and Shirasawa S: ZFAT expression in B and T lymphocytes and identification of ZFAT-regulated genes. Genomics 91(5): 451457, 2008. PMID: 18329245. DOI: 10.1016/j.ygeno.2008.01.009

3 Tsunoda T, Takashima Y, Tanaka Y, Fujimoto T, Doi K, Hirose Y, Koyanagi M, Yoshida Y, Okamura T, Kuroki M, Sasazuki $\mathrm{T}$ and Shirasawa $\mathrm{S}$ : Immune-related zinc finger gene ZFAT is an essential transcriptional regulator for hematopoietic differentiation in blood islands. Proc Natl Acad Sci USA 107(32): 14199-14204, 2010. PMID: 20660741. DOI: $10.1073 /$ pnas. 1002494107

4 Tsunoda T and Shirasawa S: Roles of ZFAT in haematopoiesis, angiogenesis and cancer development. Anticancer Res 33(7): 2833-2837, 2013. PMID: 23780967.

5 Fujimoto T, Doi K, Koyanagi M, Tsunoda T, Takashima Y, Yoshida Y, Sasazuki $T$ and Shirasawa S: ZFAT is an antiapoptotic molecule and critical for cell survival in MOLT-4 cells. FEBS Lett 583(3): 568-572, 2009. PMID: 19162026. DOI: 10.1016/j.febslet.2008.12.063

6 Doi K, Fujimoto T, Koyanagi M, Tsunoda T, Tanaka Y, Yoshida Y, Takashima Y, Kuroki M, Sasazuki T and Shirasawa S: ZFAT is a critical molecule for cell survival in mouse embryonic fibroblasts. Cell Mol Biol Lett 16(1): 89-100, 2011. PMID: 21225468. DOI: 10.2478/s11658-010-0041-1

7 Yoshida Y, Tsunoda T, Takashima Y, Fujimoto T, Doi K, Sasazuki T, Kuroki M, Iwasaki A and Shirasawa S: ZFAT is essential for endothelial cell assembly and the branch point formation of capillary-like structures in an angiogenesis model. Cell Mol Biol Lett 15(4): 541-550, 2010. PMID: 6275617. DOI: 10.2478/s11658-010-0028-y 
8 Inoue $\mathrm{N}$, Watanabe $\mathrm{M}$, Yamada $\mathrm{H}$, Takemura $\mathrm{K}$, Hayashi $\mathrm{F}$, Yamakawa N, Akahane M, Shimizuishi Y, Hidaka Y and Iwatani Y: Associations between autoimmune thyroid disease prognosis and functional polymorphisms of susceptibility genes, CTLA4, PTPN22, CD40, FCRL3, and ZFAT, previously revealed in genome-wide association studies. J Clin Immunol 32(6): 12431252, 2012. PMID: 22706687. DOI: 10.1007/s10875-012-9721-0

9 Cho YS, Go MJ, Kim YJ, Heo JY, Oh JH, Ban HJ, Yoon D, Lee MH, Kim DJ, Park M, Cha SH, Kim JW, Han BG, Min H, Ahn Y, Park MS, Han HR, Jang HY, Cho EY, Lee JE, Cho NH, Shin C, Park T, Park JW, Lee JK, Cardon L, Clarke G, McCarthy MI, Lee JY, Lee JK, Oh B and Kim HL: A large-scale genome-wide association study of Asian populations uncovers genetic factors influencing eight quantitative traits. Nat Genet 41(5): 527-534, 2009. PMID: 19396169. DOI: 10.1038/ng.357

10 Takeuchi F, Nabika T, Isono M, Katsuya T, Sugiyama T, Yamaguchi S, Kobayashi S, Yamori Y, Ogihara T and Kato N: Evaluation of genetic loci influencing adult height in the Japanese population. J Hum Genet 54(12): 749-752, 2009. PMID: 19834501. DOI: 10.1038/jhg.2009.99

11 Ramakrishna M, Williams LH, Boyle SE, Bearfoot JL, Sridhar A, Speed TP, Gorringe KL and Campbell IG: Identification of candidate growth promoting genes in ovarian cancer through integrated copy number and expression analysis. PLoS One 5(4): e9983, 2010. PMID: 20386695. DOI: 10.1371/journal.pone. 0009983

12 Slavin TP, Feng T, Schnell A, Zhu X and Elston RC: Two-marker association tests yield new disease associations for coronary artery disease and hypertension. Hum Genet 130(6): 725-733, 2011. PMID: 21626137. DOI: 10.1007/s00439-011-1009-6

13 Barbaux S, Gascoin-Lachambre G, Buffat C, Monnier P, Mondon F, Tonanny MB, Pinard A, Auer J, Bessieres B, Barlier A, Jacques $\mathrm{S}$, Simeoni U, Dandolo L, Letourneur F, Jammes H and Vaiman D: A genome-wide approach reveals novel imprinted genes expressed in the human placenta. Epigenetics 7(9): 1079-1090, 2012. PMID: 22894909. DOI: 10.4161/epi. 21495

14 Sabatino G, Rigante L, Minella D, Novelli G, Della Pepa GM, Esposito G, Albanese A, Maira G and Marchese E: Transcriptional profile characterization for the identification of peripheral blood biomarkers in patients with cerebral aneurysms. J Biol Regul Homeost Agents 27(3): 729-738, 2013. PMID: 24152840.

15 Doi K, Fujimoto T, Okamura T, Ogawa M, Tanaka Y, Mototani Y, Goto M, Ota T, Matsuzaki H, Kuroki M, Tsunoda T, Sasazuki $\mathrm{T}$ and Shirasawa S: ZFAT plays critical roles in peripheral T cell homeostasis and its T cell receptor-mediated response. Biochem Biophys Res Commun 425(1): 107-112, 2012. PMID: 22828507. DOI: $10.1016 /$ j.bbrc.2012.07.065

16 Ogawa M, Okamura T, Ishikura S, Doi K, Matsuzaki H, Tanaka Y, Ota T, Hayakawa K, Suzuki H, Tsunoda T, Sasazuki T and Shirasawa S: Zfat-deficiency results in a loss of CD3zeta phosphorylation with dysregulation of ERK and Egr activities leading to impaired positive selection. PLoS One 8(10): e76254, 2013. PMID: 24098453. DOI: 10.1371/journal.pone.0076254

17 Doi K, Ishikura $S$ and Shirasawa S: The roles of ZFAT in thymocyte differentiation and homeostasis of peripheral naive Tcells. Anticancer Res 34(8): 4489-4495, 2014. PMID: 25075091.

18 Ishikura S, Tsunoda T, Nakabayashi K, Doi K, Koyanagi M, Hayashi K, Kawai T, Tanaka Y, Iwaihara Y, Luo H, Nishi K, Okamura $\mathrm{T}$ and Shirasawa $\mathrm{S}$ : Molecular mechanisms of transcriptional regulation by the nuclear zinc-finger protein Zfat in t cells. Biochim Biophys Acta 1859(11): 1398-1410, 2016. PMID: 27591365. DOI: 10.1016/j.bbagrm.2016.08.010

19 Tsunoda T, Doi K, Ishikura S, Luo H, Nishi K, Matsuzaki H, Koyanagi M, Tanaka Y, Okamura T and Shirasawa S: Zfat expression in ZsGreen reporter gene knockin mice: Implications for a novel function of Zfat in definitive erythropoiesis. Int $\mathbf{J}$ Mol Med 42(5): 2595-2603, 2018. PMID: 30106088. DOI: 10.3892/ijmm.2018.3806

20 Ishikura S, Iwaihara Y, Tanaka Y, Luo H, Nishi K, Doi K, Koyanagi M, Okamura T, Tsunoda T and Shirasawa S: The nuclear zinc finger protein Zfat maintains FoxO1 protein levels in peripheral $\mathrm{T}$ cells by regulating the activities of autophagy and the Akt signaling pathway. J Biol Chem 291(29): 15282-15291, 2016. PMID: 27226588. DOI: 10.1074/jbc.M116.723734

21 Baron MH, Isern J and Fraser ST: The embryonic origins of erythropoiesis in mammals. Blood 119(21): 4828-4837, 2012. PMID: 3367890. DOI: 10.1182/blood-2012-01-153486

22 Tanimizu N, Nishikawa M, Saito H, Tsujimura T and Miyajima A: Isolation of hepatoblasts based on the expression of Dlk/Pref1. J Cell Sci 116(Pt 9): 1775-1786, 2003. PMID: 12665558. DOI: $10.1242 /$ jcs.00388

23 Fraser ST, Isern J and Baron MH: Maturation and enucleation of primitive erythroblasts during mouse embryogenesis is accompanied by changes in cell-surface antigen expression. Blood 109(1): 343-352, 2007. PMID: 16940424. DOI: 10.1182/ blood-2006-03-006569

24 Zhang J, Socolovsky M, Gross AW and Lodish HF: Role of Ras signaling in erythroid differentiation of mouse fetal liver cells: Functional analysis by a flow cytometry-based novel culture system. Blood 102(12): 3938-3946, 2003. PMID: 12907435. DOI: 10.1182/blood-2003-05-1479

25 Tavian $M$ and Peault B: Embryonic development of the human hematopoietic system. Int J Dev Biol 49(2-3): 243-250, 2005. PMID: 15906238. DOI: $10.1387 / \mathrm{ijdb} .041957 \mathrm{mt}$

26 Baron MH: Early patterning of the mouse embryo: Implications for hematopoietic commitment and differentiation. Exp Hematol 33(9): 1015-1020, 2005. PMID: 16140149. DOI: 10.1016/ j.exphem.2005.06.001

27 Palis J, Robertson S, Kennedy M, Wall C and Keller G: Development of erythroid and myeloid progenitors in the yolk sac and embryo proper of the mouse. Development 126(22): 5073-5084, 1999. PMID: 10529424.

28 Kingsley PD, Malik J, Fantauzzo KA and Palis J: Yolk sacderived primitive erythroblasts enucleate during mammalian embryogenesis. Blood 104(1): 19-25, 2004. PMID: 15031208. DOI: $10.1182 /$ blood-2003-12-4162

29 Cumano A and Godin I: Ontogeny of the hematopoietic system. Annu Rev Immunol 25: 745-785, 2007. PMID: 17201678. DOI: 10.1146/annurev.immunol.25.022106.141538

30 Kumaravelu P, Hook L, Morrison AM, Ure J, Zhao S, Zuyev S, Ansell J and Medvinsky A: Quantitative developmental anatomy of definitive haematopoietic stem cells/long-term repopulating units (HSC/RUs): Role of the aorta-gonad-mesonephros (AGM) region and the yolk sac in colonisation of the mouse embryonic liver. Development 129(21): 4891-4899, 2002. PMID: 12397098.

31 Pop R, Shearstone JR, Shen Q, Liu Y, Hallstrom K, Koulnis M, Gribnau J and Socolovsky M: A key commitment step in erythropoiesis is synchronized with the cell cycle clock through mutual inhibition between PU.1 and S-phase progression. PLoS Biol 8(9), 2010. PMID: 20877475. DOI: 10.1371/journal.pbio. 1000484 
32 Wang H, Boussouar A, Mazelin L, Tauszig-Delamasure S, Sun Y, Goldschneider D, Paradisi A and Mehlen P: The protooncogene c-Kit inhibits tumor growth by behaving as a dependence receptor. Mol Cell 72(3): 413-425 e415, 2018. PMID: 30293784. DOI: 10.1016/j.molcel.2018.08.040

33 Boddu P, Benton CB, Wang W, Borthakur G, Khoury JD and Pemmaraju N: Erythroleukemia-historical perspectives and recent advances in diagnosis and management. Blood Rev 32(2): 96-105, 2018. PMID: 28965757. DOI: 10.1016/j.blre.2017.09.002

34 Cantor $\mathrm{AB}$ and Orkin $\mathrm{SH}$ : Transcriptional regulation of erythropoiesis: An affair involving multiple partners. Oncogene 21(21): 3368-3376, 2002. PMID: 12032775. DOI: 10.1038/ sj.onc. 1205326

35 Dore LC and Crispino JD: Transcription factor networks in erythroid cell and megakaryocyte development. Blood 118(2): 231239, 2011. PMID: 21622645. DOI: 10.1182/blood-2011-04-285981

36 Palis J: Primitive and definitive erythropoiesis in mammals. Front Physiol 5: 3, 2014. PMID: 24478716. DOI: 10.3389/fphys. 2014.00003
37 Koulnis M, Porpiglia E, Porpiglia PA, Liu Y, Hallstrom K, Hidalgo D and Socolovsky M: Contrasting dynamic responses in vivo of the $\mathrm{Bcl}-\mathrm{xL}$ and $\mathrm{Bim}$ erythropoietic survival pathways. Blood 119(5): 1228-1239, 2012. PMID: 22086418. DOI: 10.1182/blood-2011-07-365346

38 Liu Y, Pop R, Sadegh C, Brugnara C, Haase VH and Socolovsky M: Suppression of Fas-FasL coexpression by erythropoietin mediates erythroblast expansion during the erythropoietic stress response in vivo. Blood 108(1): 123-133, 2006. PMID: 165278 92. DOI: $10.1182 /$ blood-2005-11-4458
Received May 23, 2019

Revised June 20, 2019

Accepted June 24, 2019 